\title{
Cognitive Function Is a Prognostic Factor for Mortality of Nursing Home Residents during a 3-Year Observational Period
}

\author{
Dorota Pytka Bozena Czarkowska-Paczek \\ Department of Clinical Nursing, Medical University of Warsaw, Warsaw, Poland
}

\section{Keywords}

Nursing home residents · Cognitive function · Mortality

\begin{abstract}
Introduction: Assessing cognitive function could help to provide appropriate care for nursing home residents. The aim of the study was to identify the factors affecting cognitive function in nursing home residents in Poland and assess how it influenced the mortality rate during a 3-year observational period. Methods: This study included 202 elderly individuals from a nursing home in 2015. The investigation included examination of cognitive function using the MMSE and bioelectrical impedance analysis. Collected data included sex, age, blood pressure (BP), heart rate, number of comorbidities, years spent in the nursing home, educational level, and cigarette-smoking. Results: The mean MMSE score was $21.36 \pm 6.35$, which was negatively correlated with age and diastolic $\operatorname{BP}(p=0.001$ and $p=0.024$, respectively) and positively correlated with body mass, BMI, fat-free mass, fat, muscle mass, and education level $(p=0.004, p=0.004, p=002, p=0.049, p=0.005$, and $p<0.001$, respectively). Patients who died during the observational period had lower MMSE scores than those who survived (23.34 \pm 5.68 vs. $20.16 \pm 6.45 ; p<0.001)$. Smokers had better MMSE results than nonsmokers (23.34 \pm 5.98 vs. $20.08 \pm 4.94 ; p<0.001$ ). Discussion: Polish nursing home residents had mild cognitive impairment depending on their age, sex, educational level, and nutritional status. Lower MMSE score was a prognostic factor for mortality in the 3-year observational period.
\end{abstract}

\section{Introduction}

Older people can suffer from a number of different conditions, including comorbidity and dementia, which result in susceptibility to different stimuli that are detrimental to their health. 
Dementia encompasses a loss of cognitive function and the ability to perform the activities of daily living. It results from neurodegenerative disorders and includes several subtypes. The symptoms of dementia are progressive and long-lasting [1], and affect $6-8 \%$ of individuals $\geq 60$ years of age, and up to $25 \%$ of individuals $\geq 85$ years of age [2]. Since old age is a major risk factor for dementia, the dementia rate will rise in the coming years as the population ages [3]. It is estimated that 50 million people globally had dementia in 2018, and that this number will rise to 152 million by 2050 [4].

People suffering from dementia have special care needs resulting from cognitive and functional impairment, difficulty communicating, and other neuropsychiatric symptoms. Diagnosis of dementia can have numerous benefits. It can potentially enable immediate initiation of treatment and adjustment of medications to reduce any side effects that influence cognitive functions. It may also help to ensure adequate support for patients and their families and allow them to make plans for the future [5]. In nursing practice, knowledge about cognitive impairments and rehabilitation techniques is crucial since each type of activity may have a therapeutic effect on the patient. Assessment of the cognitive functions of elderly patients enables customization of the type of care provided according to the severity of the cognitive impairment, potentially including assistance with everyday living, home-based care, institutional daycare, or round-the-clock care in a residential facility.

Residents of nursing homes have a higher burden of dementia that those found in the general population [6]. Despite the benefits of an early diagnosis of cognitive impairment, a missed diagnosis could lead to inappropriate treatment and even increase the incidence of challenging behaviors due to the patient's needs not being met. The Mini-Mental State Examination (MMSE) is used to assess cognitive impairment in the clinical and research settings. It is a short, easy to apply, commonly accepted, and available tool.

The aim of this study was to assess cognitive function in the elderly residents of a nursing home in Poland, by identifying the factors affecting it, and determining its influence on the mortality rate.

\section{Methods}

\section{Participants and Procedure}

The cross-sectional study was conducted at a nursing home in Warsaw, Poland, in 2015. The investigated group comprised 202 residents. The inclusion criterion was the capacity of the patient to give informed consent. To assess the influence of cognitive function on the mortality rate, an assessment of the number of survivors and those who had died was made after 3 years. During this period, $126(62.37 \%)$ patients died. The study protocol included a cognitive function evaluation using the MMSE, Polish version [7], and bioelectrical impedance analysis using the BioScan 920-2 (Maltron Int. Ltd., Rayleigh, UK). The MMSE consists of 11 items that test 5 areas of cognitive function: orientation registration, attention and calculation, recall, and language. The possible score ranges from 0 to 30 , where $>24=$ normal cognitive function, $19-23=$ mild, $9-18=$ moderate, and $<9=$ severe impairment of cognitive function.

Sociodemographic data were obtained from the study-specific questionnaire and medical documentation. Data collected included age, sex, blood pressure (BP), heart rate, comorbidities, years spent in the nursing home, educational level, and cigarette-smoking. In the analysis, comorbidities were generalized to "number of comorbidities." Due to only a few different diseases being identified, i.e., cardiovascular diseases, diabetes, and respiratory disease, separate analyses were not possible. Smokers were those who smoked on a daily basis. The participants' names were not recorded on the questionnaire, thus rendering the data anonymous. All investigations were completed on one occasion and on site.

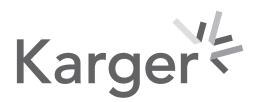


Table 1. Characteristics of the investigated group, stratified by sex

\begin{tabular}{|c|c|c|c|c|c|c|}
\hline & \multicolumn{2}{|c|}{ Total group $(n=202)$} & \multicolumn{2}{|l|}{ Males $(n=45)$} & \multicolumn{2}{|c|}{ Females $(n=157)$} \\
\hline & mean \pm SD & median; $\min -\max$ & mean $\pm S D$ & median; $\min -\max$ & mean \pm SD & median; min-max \\
\hline Age, years & $82.16 \pm 8.58$ & $83 ; 65-99$ & $81.67 \pm 9.21$ & $83 ; 65-96$ & $82.31 \pm 8.41$ & $83 ; 65-99$ \\
\hline Body mass, kg & $65.53 \pm 14.75$ & $65 ; 34-118$ & $71.4 \pm 14.25$ & $73 ; 39-98$ & $63.85 \pm 14.50$ & $64 ; 34-118$ \\
\hline BMI & $25.11 \pm 5.61$ & $24.95 ; 13.2-42.2$ & $25.36 \pm 4.64$ & $25.4 ; 16.2-33.9$ & $25.03 \pm 5.87$ & $24.8 ; 13.2-42.2$ \\
\hline FFM, kg & $43.37 \pm 7.55$ & $42.06 ; 28.05-74.05$ & $51.70 \pm 8.61$ & $52.67 ; 30.66-74.05$ & $40.98 \pm 5.18$ & $41.04 ; 28.05-56.83$ \\
\hline Fat, kg & $22.16 \pm 10.56$ & $21.75 ; 4.36-61.17$ & $19.77 \pm 8.64$ & $18.24 ; 8.04-40.27$ & $22.84 \pm 10.98$ & $22.07 ; 4.63-61.17$ \\
\hline Muscle mass, $\mathrm{kg}$ & $20.40 \pm 10.97$ & $18.21 ; 10.77-94.97$ & $26.01 \pm 9.67$ & $25.43 ; 12.97-83.62$ & $18.79 \pm 10.81$ & $17.31 ; 10.77-94.97$ \\
\hline SBP, mm Hg & $120.07 \pm 20.09$ & $119 ; 75-186$ & $118.51 \pm 25.09$ & 111; 86-186 & $120.52 \pm 18.48$ & $120 ; 75-167$ \\
\hline DBP, $\mathrm{mm} \mathrm{Hg}$ & $71.29 \pm 12.42$ & $70 ; 42-134$ & $69.87 \pm 13.39$ & $66 ; 42-105$ & $71.70 \pm 12.12$ & $70 ; 50-134$ \\
\hline $\mathrm{HR}$, beats/min & $74.24 \pm 12.00$ & $74 ; 51-112$ & $72.38 \pm 11.69$ & $73 ; 53-105$ & $74.77 \pm 12.07$ & $74 ; 51-112$ \\
\hline $\begin{array}{l}\text { Years resident in nursing } \\
\text { home }\end{array}$ & $3.44 \pm 4.04$ & $2 ; 1-44$ & $3.22 \pm 2.98$ & $2 ; 1-14$ & $3.49 \pm 4.30$ & $2 ; 1-44$ \\
\hline Smokers, $n(\%)$ & & $66(32.67)$ & \multicolumn{2}{|c|}{$24(53.33)$} & \multicolumn{2}{|l|}{$42(26.75)$} \\
\hline \multicolumn{7}{|l|}{ Alcohol consumption, $n(\%)$} \\
\hline None & & $162(80.2)$ & \multicolumn{2}{|c|}{$17(37.78)$} & \multicolumn{2}{|l|}{$145(92.36)$} \\
\hline$<2$ units/week & & $16(7.92)$ & \multicolumn{2}{|c|}{$10(22.22)$} & \multicolumn{2}{|l|}{$6(3.82)$} \\
\hline$>2$ units/week & & $24(11.88)$ & \multicolumn{2}{|c|}{$18(40)$} & \multicolumn{2}{|l|}{$6(3.82)$} \\
\hline \multicolumn{7}{|l|}{ Comorbidities, $n(\%)$} \\
\hline 0 & & $10(4.95)$ & \multicolumn{2}{|c|}{$3(6.67)$} & \multicolumn{2}{|l|}{$7(4.46)$} \\
\hline 1 & & $122(60.4)$ & \multicolumn{2}{|c|}{$28(62.22)$} & \multicolumn{2}{|l|}{$94(59.87)$} \\
\hline 2 & & 65 (32.18) & \multicolumn{2}{|c|}{$11(24.44)$} & \multicolumn{2}{|l|}{$54(34.40)$} \\
\hline 3 & & $5(2.47)$ & \multicolumn{2}{|c|}{$3(6.67)$} & \multicolumn{2}{|l|}{$2(1.27)$} \\
\hline \multicolumn{7}{|l|}{ Education level, $n(\%)$} \\
\hline Elementary school & & $94(46.54)$ & \multicolumn{2}{|c|}{$18(40)$} & \multicolumn{2}{|l|}{$76(48.41)$} \\
\hline Vocational school & & $21(10.4)$ & \multicolumn{2}{|c|}{3 (6.67) } & \multicolumn{2}{|l|}{$18(11.46)$} \\
\hline High school & & $71(35.15)$ & \multicolumn{2}{|c|}{$19(42.22)$} & \multicolumn{2}{|l|}{$52(33.12)$} \\
\hline University & & $16(7.91)$ & \multicolumn{2}{|c|}{5 (11.11) } & \multicolumn{2}{|l|}{$11(7.01)$} \\
\hline \multicolumn{7}{|l|}{ Place of residence, $n(\%)$} \\
\hline Village & & $30(14.85)$ & & $(22.22)$ & $20(12.74)$ & \\
\hline Town & & $172(85.15)$ & & $(77.78)$ & $137(87.26)$ & \\
\hline
\end{tabular}

BMI, body mass index; FFM, fat-free mass; SBP, systolic blood pressure; DBP, diastolic blood pressure; HR, heart rate.

\section{Statistical Analysis}

Statistical analysis was performed using IBM SPSS v23. Descriptive statistics were generated using standard parameters, including percentage, mean and standard deviation, and median and range. The Kolmogorov-Smirnov test revealed that the MMSE results did not show a normal distribution, so nonparametric tests were used for all calculations.

Between-group differences were analyzed using the Mann-Whitney U test or the KruskalWallis test. The Spearman test was used to analyze correlations between MMSE scores and the investigated parameters. The preliminary selection of variables for logistic regression models was carried out based on the prior statistical tests. The assumed level of significance of potential variables that could be included in the model was $p<0.1$. Subsequently, the stepwise selection algorithm with the Akaike information criterion was applied to the variables selected in the above manner. Survivability curves were plotted using the Kaplan-Meier estimator. Results were considered statistically significant when $p<0.05$.

\section{Results}

The investigated group consisted of 202 participants, including females $(n=157,77$, $72 \%)$ and males $(n=45,22,78 \%)$. The demographic and clinical characterization of the participants stratified by sex is shown in Table 1 . 


\section{Dementia and Geriatric Cognitive Disorders Extra}

Dement Geriatr Cogn Disord Extra 2020;10:163-171

Pytka and Czarkowska-Paczek: Cognitive Functions Is a Prognostic Factor for Mortality

Table 2. Mini-Mental State Examination (MMSE) results stratified by sex and differences between females and males

\begin{tabular}{|c|c|c|c|c|c|c|c|}
\hline \multirow[t]{2}{*}{ MMSE scores } & \multicolumn{2}{|c|}{ Total $(n=202)$} & \multicolumn{2}{|c|}{ Males $(n=45)$} & \multicolumn{2}{|c|}{ Females $(n=157)$} & \multirow[t]{2}{*}{$p$ value } \\
\hline & mean $\pm S D$ & $\begin{array}{l}\text { median } \\
\text { (range) }\end{array}$ & mean $\pm S D$ & $\begin{array}{l}\text { median } \\
\text { (range) }\end{array}$ & mean \pm SD & $\begin{array}{l}\text { median } \\
\text { (range) }\end{array}$ & \\
\hline Total/task & $21.36 \pm 6.35$ & $22.50(4-30)$ & $22.78 \pm 5.83$ & $25(8-30)$ & $20.95 \pm 6.43$ & $22(4-30)$ & 0.081 \\
\hline Orientation to time & $4.21 \pm 1.24$ & $5(0-5)$ & $4.56 \pm 0.89$ & $5(2-5)$ & $4.11 \pm 1.31$ & $5(0-5)$ & 0.030 \\
\hline Orientation to place & $4.31 \pm 1.08$ & $5(1-5)$ & $4.62 \pm 0.75$ & 5 & $4.22 \pm 1.15$ & $5(1-5)$ & 0.057 \\
\hline Registration & $2.50 \pm 1.08$ & $3(0-3)$ & $2.58 \pm 0.97$ & $3(0-3)$ & $2.48 \pm 1.11$ & $3(0-3)$ & 0.786 \\
\hline Attention and calculation & $2.34 \pm 2.09$ & $2(0-5)$ & $2.91 \pm 2.08$ & $4(0-5)$ & $2.18 \pm 2.08$ & $1(0-5)$ & 0.035 \\
\hline Recall & $0.6 \pm 1.02$ & $0(0-3)$ & $0.53 \pm 0.94$ & $0(0-3)$ & $0.62 \pm 1.04$ & $0(0-3)$ & 0.746 \\
\hline Naming & $1.95 \pm 0.32$ & $2(0-2)$ & $1.93 \pm 0.33$ & $2(0-2)$ & $1.95 \pm 0.32$ & $2(0-2)$ & 0.523 \\
\hline Repetition & $0.84 \pm 0.37$ & $1(0-1)$ & $0.84 \pm 0.37$ & $1(0-1)$ & $0.83 \pm 0.37$ & $1(0-1)$ & 0.873 \\
\hline Comprehension & $2.56 \pm 1.05$ & $3(0-3)$ & $2.62 \pm 0.98$ & $3(0-3)$ & $2.54 \pm 1.07$ & $3(0-3)$ & 0.660 \\
\hline Reading & $0.72 \pm 0.45$ & $1(0-1)$ & $0.73 \pm 0.45$ & $1(0-1)$ & $0.72 \pm 0.45$ & $1(0-1)$ & 0.858 \\
\hline Writing & $0.67 \pm 0.47$ & $1(0-1)$ & $0.71 \pm 0.46$ & $1(0-1)$ & $0.66 \pm 0.47$ & $1(0-1)$ & 0.540 \\
\hline Drawing & $0.64 \pm 0.48$ & $1(0-1)$ & $0.73 \pm 0.45$ & $1(0-1)$ & $0.62 \pm 0.49$ & $1(0-1)$ & 0.155 \\
\hline
\end{tabular}

Table 3. Correlations between Mini-Mental State Examination (MMSE) results and selected parameters, with stratification by sex

\begin{tabular}{|c|c|c|c|}
\hline & \multicolumn{3}{|l|}{ MMSE } \\
\hline & $\begin{array}{l}\text { whole group } \\
(n=202)\end{array}$ & $\begin{array}{l}\text { males } \\
(n=45)\end{array}$ & $\begin{array}{l}\text { females } \\
(n=157)\end{array}$ \\
\hline Age, years & $\begin{array}{l}\rho=-0.234 \\
p=0.001\end{array}$ & $\begin{array}{l}\rho=-0.308 \\
p=0.040\end{array}$ & $\begin{array}{l}\rho=-0.209 \\
p=0.009\end{array}$ \\
\hline Body mass, kg & $\begin{array}{l}\rho=0.201 \\
p=0.004\end{array}$ & $\begin{array}{l}\rho=0.100 \\
p=0.513\end{array}$ & $\begin{array}{l}\rho=0.216 \\
p=0.006\end{array}$ \\
\hline BMI & $\begin{array}{l}\rho=0.201 \\
p=0.004\end{array}$ & $\begin{array}{l}\rho=0.155 \\
p=0.311\end{array}$ & $\begin{array}{l}\rho=0.210 \\
p=0.008\end{array}$ \\
\hline FFM, kg & $\begin{array}{l}\rho=0.213 \\
p=0.002\end{array}$ & $\begin{array}{l}\rho=0.157 \\
p=0.303\end{array}$ & $\begin{array}{l}\rho=0.189 \\
p=0.018\end{array}$ \\
\hline Fat, kg & $\begin{array}{l}\rho=0.138 \\
p=0.049\end{array}$ & $\begin{array}{l}\rho=-0.005 \\
p=0.976\end{array}$ & $\begin{array}{l}\rho=0.198 \\
p=0.013\end{array}$ \\
\hline Muscle mass, kg & $\begin{array}{l}\rho=0.197 \\
p=0.005\end{array}$ & $\begin{array}{l}\rho=0.106 \\
p=0.487\end{array}$ & $\begin{array}{l}\rho=0.190 \\
p=0.017\end{array}$ \\
\hline SBP, mm Hg & $\begin{array}{l}\rho=-0.082 \\
p=0.244\end{array}$ & $\begin{array}{l}\rho=-0.059 \\
p=0.698\end{array}$ & $\begin{array}{l}\rho=-0.083 \\
p=0.303\end{array}$ \\
\hline DBP, mm Hg & $\begin{array}{l}\rho=-0.158 \\
p=0.024\end{array}$ & $\begin{array}{l}\rho=-0.125 \\
p=0.414\end{array}$ & $\begin{array}{l}\rho=-0.173 \\
p=0.030\end{array}$ \\
\hline HR, beats/min & $\begin{array}{l}\rho=-0.071 \\
p=0.317\end{array}$ & $\begin{array}{l}\rho=-0.226 \\
p=0.135\end{array}$ & $\begin{array}{l}\rho=-0.024 \\
p=0.768\end{array}$ \\
\hline Level of education & $\begin{array}{l}\rho=0.326 \\
p<0.001\end{array}$ & $\begin{array}{l}\rho=0.079 \\
p=0.608\end{array}$ & $\begin{array}{l}\rho=0.383 \\
p<0.001\end{array}$ \\
\hline Years resident in nursing home & $\begin{array}{l}\rho=-0.050 \\
p=0.481\end{array}$ & $\begin{array}{l}\rho=-0.009 \\
p=0.952\end{array}$ & $\begin{array}{l}\rho=-0.043 \\
p=0.592\end{array}$ \\
\hline
\end{tabular}

BMI, body mass index; FFM, fat-free mass; SBP, systolic blood pressure; DBP, diastolic blood pressure; HR, heart rate. 


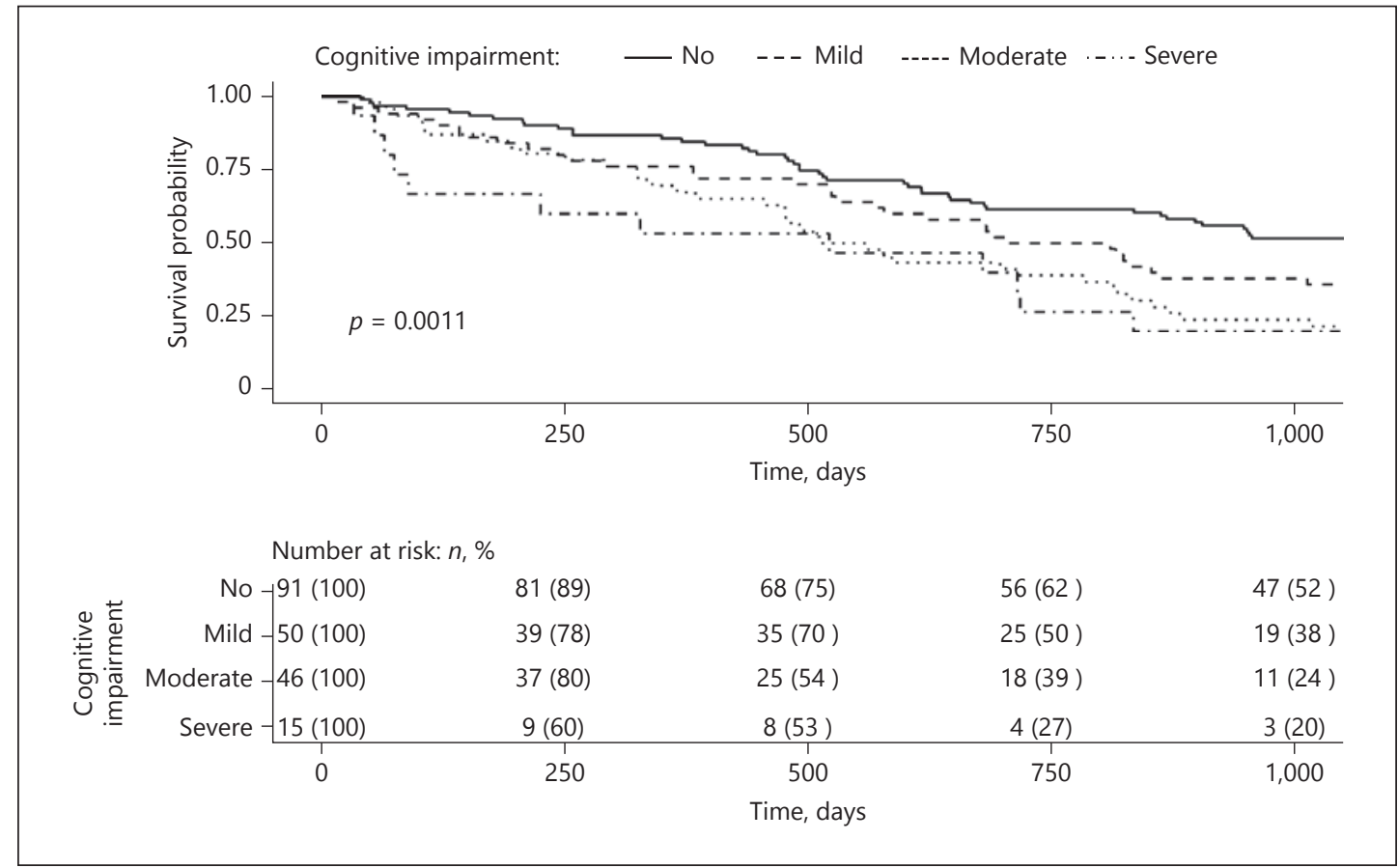

Fig. 1. Kaplan-Meyer survival curves for patients with different impairment of cognitive function assessed with the use of the MMSE.

The mean MMSE score was $21.36 \pm 6.35$, indicating mild cognitive impairment. The results of MMSE subscales stratified by sex are shown in Table 2. Total MMSE results did not significantly differ between women and men. However, men had significantly better MMSE scores for "orientation to time" ( $p=0.03)$ and "attention and calculation" ( $p=0.035)$.

The correlations between MMSE results and selected parameters with stratification by sex is shown in Table 3.

MMSE scores were negatively correlated with age, both in the whole investigated group and men and women separately. In the whole group and among women, but not among men, MMSE results were positively correlated with body mass, body mass index (BMI), fat-free mass (FFM), fat, muscle mass, and education level, and negatively correlated with diastolic BP (DBP).

Smokers had better MMSE scores than nonsmokers (23.34 \pm 5.98 vs. $20.08 \pm 4.94 ; p<$ 0.001). MMSE score was not significantly associated with the number of comorbidities.

Compared to patients who died during the observational period $(n=126)$, survivors $(n=76)$ had significantly better MMSE scores (23.34 \pm 5.68 vs. $20.16 \pm 6.45 ; p<0.001)$. Applying backward stepwise regression, the model explaining the risk of dying during the 3 -year observation was obtained (and covers MMSE, age, and DBP). Each point scored on the MMSE scale decreased the risk of the patient's death by $9.19 \%$ on average, assuming that the other factors remained unchanged. Each subsequent year lived by the patient increased the risk of death by $6.4 \%$ on average, assuming that the other factors remained unchanged. DBP found to be higher by 1 unit $(\mathrm{Hg}$ ) decreased the risk of death by $3.13 \%$ on average, assuming that the other factors remained unchanged.

Survival curves in groups with normal cognitive function, or mild, moderate, or severe impairment of cognitive function, were plotted using the Kaplan-Meier estimator and appear in Figure 1. The log rank test revealed a statistically significant difference between the groups $(p=0.0011)$.

\section{Karger'}




\section{Discussion}

The average MMSE score among study participants indicated mild cognitive impairment and was higher than the results obtained by Kowalska et al. [8] who investigated 254 people admitted to a nursing home in Wrocław (Poland) between 2007 and 2010. Similar study of residents in care homes in Spain [9] and the UK [10] also indicated lower scores than in our study. MMSE scores of our participants were similar to the results obtained by Weidung et al. [11], who investigated very elderly people who were not resident in of nursing homes. In our study, BP, heart rate, and BMI were all in the normal range, suggesting that our participants enjoyed good health, in contrast to those in the abovementioned studies. Our participants had, on average, only 1 disease. In general, the median number of chronic conditions in the population of people $>65$ years of age is 3 [12]. Differences in MMSE scores may be attributable to the different criteria for admission to nursing homes in Poland and other countries, and that Polish nursing home residents are generally in a better cognitive and physical condition than patients admitted to such facilities in other countries.

Our results showed a higher general MMSE score for men than women, although this difference was not significant. Other researchers have also reported better cognitive results in men $[13,14]$. We found that men had significantly higher scores in the categories of "orientation to time" and "attention and calculation." This could be related to the fact that our study included more women than men. However, we cannot exclude the role of confounding factors such as social life, lower education level, or type of work $[13,14]$.

MMSE score was negatively correlated with age and positively correlated with education level, in line with findings by other authors $[15,16]$. The correlation with age was expected since age is the most well-recognized risk factor for dementia [13]. To explain the relationship between low education level and cognitive decline, various mechanisms have been proposed, including a hypothesis involving lower brain reserve and a lack of occupational activities leading to lower intellectual demands, a proposal relating to low cognitive stimulation throughout life [16] and the concept that lower education level is related to reduced access to intellectually stimulating entertainment [15].

MMSE scores were positively correlated with body mass, BMI, FFM, muscle mass, and fat. Higher BMI and fat may contribute to maintaining better cognitive functions during the ageing process [17]. However, the associations of body mass and BMI with the risk of dementia are far from clear. Overweight and obese individuals carry a higher risk of developing diseases that influence cognitive function [18]. However, in later life, the detrimental consequences of being obese or overweight are less apparent, and there may even be protective effects [19]. Importantly, weight loss is a frequent side effect of dementia and might worsen outcomes in elderly patients. Therefore, patients with cognitive dysfunction should be regularly screened for malnutrition to enable early nutritional intervention.

MMSE scores were negatively correlated with DBP, in line with the findings of other studies [20]. Surprisingly, we did not detect an association between systolic BP (SBP) and cognitive function level. The mechanisms underlying the association between arterial hypertension and impaired cognition are not completely understood. High DBP may decrease tissue perfusion. It is possible that a higher SBP is needed to maintain brain perfusion in older individuals [21]. On the other hand, high BP directly or indirectly causes cerebral vascular damage which can lead to dementia [22].

Previous evidence indicates that impaired cognitive function is an independent predictor of mortality in elderly individuals, after accounting for numerous different variables $[23,24]$. It has been suggested that the association between cognitive dysfunction and mortality reflects a global deterioration of health status that both affects cognitive functions and directly contributes to mortality [25]. Our data confirm that the patients who died

\section{Karger'}


during the 3-year observation period had worse MMSE results than those who survived the entire observation period. Cognitive impairment complicates neurological and cerebrovascular diseases, and other chronic illnesses, which are known risk factors for mortality [26]. However, while higher mortality is reportedly associated with moderate-to-severe cognitive impairment, its correlation with milder cognitive impairments is less obvious [27]. We did not show a correlation between multiple morbidity and the MMSE results, which has been identified in other studies [28]. Such correlations are in line with the dynamic polygon hypothesis, which considers that several pathological processes (e.g., amyloid aggregation or vascular damage), interlinked with the positive or negative consequences of environmental exposure (e.g., exercise or obesity), will potentially influence the size and functioning of the brain [29].

Cigarette-smoking was correlated with a higher MMSE score, which has not been previously reported [30]. The mechanisms by which smoking affects cognitive performance remain unclear [31]. Some evidence suggests that the impact of smoking on adverse cognitive outcomes may be underestimated due to the selection effects resulting from the higher midlife mortality of smokers [32]. Our findings may have been affected by the selection of the sample group. On the other hand, nicotine increases acetylcholine release, elevates the number of nicotinic receptors, and improves attention and informationprocessing, although these actions may be opposed by the high oxidative stress caused by smoking [31].

The study has some limitations. The inclusion criterion was the capacity to give informed consent for participation, which could have resulted in an underestimation of the prevalence of cognitive impairment in the nursing home residents. We also conducted our study in only 1 nursing home in Warsaw. Our assessment was based only on the MMSE and not on a full cognitive evaluation. The results may partly be explained by the effect of the selective survival of the study participants. Mortality rate is also influenced by other factors and conditions not assessed in this study, e.g., frailty syndrome and metabolic disorders.

\section{Conclusions}

Our findings showed that nursing home residents in Poland had higher cognitive function, as indicated by MMSE score, than nursing home residents in other countries. This may be attributable to variable admission criteria and our patients being in a better cognitive and physical condition than the patients admitted to such facilities in other countries. We demonstrated that the MMSE scores were associated with patients' sex, age, education, and nutritional status. The relationship found between MMSE score and cigarette-smoking could be coincidental.

A lower MMSE score was associated with a higher mortality rate during 3-year observational period. We propose using MMSE as a tool for screening cognitive function and determining prognostic factors for the mortality of nursing home residents.

\section{Acknowledgments}

The English version was edited by San Francisco Edit. 


\section{Geriatric Cognitive Disorders Extra}

\section{Statement of Ethics}

The study protocol was approved by the Bioethics Committee of the Medical University of Warsaw (No. KB/13/2015, dated February 17, 2015). Each participant received instructions from the author explaining the purpose of the study and ensuring confidentiality. Every person enrolled in the study provided written informed consent to participate.

\section{Conflict of Interest Statement}

The authors have no conflicts of interest to declare.

\section{Funding Sources}

This research did not receive any specific grant from funding agencies in the public, commercial, or not-for-profit sectors.

\section{Author Contributions}

D.P.: design of the study, collecting data, interpretation of results, literature collection, writing of manuscript; B.C.-P.: design of the study, interpretation of results, writing of the manuscript.

\section{References}

1 Arevalo-Rodriguez I, Smailagic N, Roqué I Figuls M, Ciapponi A, Sanchez-Perez E, Giannakou A, et al. MiniMental State Examination (MMSE) for the detection of Alzheimer's disease and other dementias in people with mild cognitive impairment (MCI). Cochrane Database Syst Rev. 2015 Mar;3(3):CD010783.

2 Prince M, Bryce R, Albanese E, Wimo A, Ribeiro W, Ferri CP. The global prevalence of dementia: a systematic review and metaanalysis. Alzheimers Dement. 2013 Jan;9(1):63-75.e2.

3 Winblad I, Viramo P, Remes A, Manninen M, Jokelainen J. Prevalence of dementia - a rising challenge among ageing populations. Eur Geriatr Med. 2010;1(6):330-3.

4 Report WA. The state of the art of dementia research: New frontiers. Published by Alzheimer's Disease International. London: ADI; 2018.

5 Iliffe S, Manthorpe J, Eden A. Sooner or later? Issues in the early diagnosis of dementia in general practice: a qualitative study. Fam Pract. 2003 Aug;20(4):376-81.

6 Van Rensbergen G, Nawrot T. Medical conditions of nursing home admissions. BMC Geriatr. 2010 Jul;10(1): 46.

7 Stanczak J. MMSE Polska normalizacja. Warszawa: Pracownia Testów Psychologicznych Polskiego Towarzystwa Psychologicznego; 2013.

8 Kowalska J, Rymaszewska J, Szczepańska-Gieracha J. Occurrence of cognitive impairment and depressive symptoms among the elderly in a nursing home facility. Adv Clin Exp Med. 2013 Jan-Feb;22(1):111-7.

9 de la Rica-Escuín M, González-Vaca J, Varela-Pérez R, Arjonilla-García MD, Silva-Iglesias M, Oliver-Carbonell $\mathrm{JL}$, et al. Frailty and mortality or incident disability in institutionalized older adults: the FINAL study. Maturitas. 2014 Aug;78(4):329-34.

10 Gordon AL, Franklin M, Bradshaw L, Logan P, Elliott R, Gladman JR. Health status of UK care home residents: a cohort study. Age Ageing. 2014 Jan;43(1):97-103.

11 Weidung B, Littbrand H, Nordström P, Carlberg B, Gustafson Y. The association between SBP and mortality risk differs with level of cognitive function in very old individuals. J Hypertens. 2016 Apr;34(4):745-52.

12 Bähler C, Huber CA, Brüngger B, Reich O. Multimorbidity, health care utilization and costs in an elderly community-dwelling population: a claims data based observational study. BMC Health Serv Res. 2015 Jan; 15(1):23. 
13 Pradier C, Sakarovitch C, Le Duff F, Layese R, Metelkina A, Anthony S, et al. The mini mental state examination at the time of Alzheimer's disease and related disorders diagnosis, according to age, education, gender and place of residence: a cross-sectional study among the French National Alzheimer database. PLoS One. 2014 Aug;9(8):e103630.

14 Lyu J, Kim HY. Gender-Specific Incidence and Predictors of Cognitive Impairment among Older Koreans: Findings from a 6-Year Prospective Cohort Study. Psychiatry Investig. 2016 Sep;13(5):473-9.

15 Klich-Rączka A, Piotrowicz K, Mossakowska M, Skalska A, Wizner B, Broczek K, et al. The assessment of cognitive impairment suspected of dementia in Polish elderly people: results of the population-based PolSenior Study. Exp Gerontol. 2014 Sep;57:233-42.

16 Wajman JR, Oliveira FF, Schultz RR, Marin SM, Bertolucci PH. Educational bias in the assessment of severe dementia: Brazilian cutoffs for severe Mini-Mental State Examination. Arq Neuropsiquiatr. 2014 Apr;72(4): 273-7.

17 Tikhonoff V, Casiglia E, Guidotti F, Giordano N, Martini B, Mazza A, et al. Body fat and the cognitive pattern: A population-based study. Obesity (Silver Spring). 2015 Jul;23(7):1502-10.

18 Gallucci M, Mazzuco S, Ongaro F, Di Giorgi E, Mecocci P, Cesari M, et al. Body mass index, lifestyles, physical performance and cognitive decline: the "Treviso Longeva (TRELONG)" study. J Nutr Health Aging. 2013 Apr; 17(4):378-84.

19 Emmerzaal TL, Kiliaan AJ, Gustafson DR. 2003-2013: a decade of body mass index, Alzheimer's disease, and dementia. J Alzheimers Dis. 2015;43(3):739-55.

20 Post Hospers G, Smulders YM, Maier AB, Deeg DJ, Muller M. Relation between blood pressure and mortality risk in an older population: role of chronological and biological age. J Intern Med. 2015 Apr;277(4):488-97.

21 Scuteri A, Nilsson PM, Tzourio C, Redon J, Laurent S. Microvascular brain damage with aging and hypertension: pathophysiological consideration and clinical implications. J Hypertens. 2011 Aug;29(8):1469-77.

22 Giordano N, Tikhonoff V, Palatini P, Bascelli A, Boschetti G, De Lazzari F, et al. Cognitive functions and cognitive reserve in relation to blood pressure components in a population-based cohort aged 53 to 94 years. Int J Hypertens. 2012;2012:274851.

23 Gustafson DR, Mazzuco S, Ongaro F, Antuono P, Forloni G, Albani D, et al. Body mass index, cognition, disability, APOE genotype, and mortality: the “Treviso Longeva” Study. Am J Geriatr Psychiatry. 2012 Jul;20(7):594-602.

24 Takata Y, Ansai T, Soh I, Awano S, Nakamichi I, Akifusa S, et al. Cognitive function and 10 year mortality in an 85 year-old community-dwelling population. Clin Interv Aging. 2014 Oct;9:1691-9.

25 Nguyen HT, Black SA, Ray LA, Espino DV, Markides KS. Cognitive impairment and mortality in older mexican americans. J Am Geriatr Soc. 2003 Feb;51(2):178-83.

26 Wolfe CD, Crichton SL, Heuschmann PU, McKevitt CJ, Toschke AM, Grieve AP, et al. Estimates of outcomes up to ten years after stroke: analysis from the prospective South London Stroke Register. PLoS Med. 2011 May; 8(5):e1001033.

27 Park MH, Kwon DY, Jung JM, Han C, Jo I, Jo SA. Mini-Mental Status Examination as predictors of mortality in the elderly. Acta Psychiatr Scand. 2013 Apr;127(4):298-304.

28 Melis RJ, Marengoni A, Rizzuto D. eerenstra S, Kivipelto M, Angleman SB, Fratiglioni L. The influence of multimorbidity on clinical progression of dementia in a population-based cohort. PLoS One. 2013;30:8.

29 Fotuhi M, Hachinski V, Whitehouse PJ. Changing perspectives regarding late-life dementia. Nat Rev Neurol. 2009 Dec;5(12):649-58.

30 Lo AH, Woodman RJ, Pachana NA, Byrne GJ, Sachdev PS. Associations between lifestyle and cognitive function over time in women aged 40-79 years. J Alzheimers Dis. 2014;39(2):371-83.

31 Reitz C, Luchsinger J, Tang MX, Mayeux R. Effect of smoking and time on cognitive function in the elderly without dementia. Neurology. 2005 Sep;65(6):870-5.

32 Hernán MA, Alonso A, Logroscino G. Cigarette smoking and dementia: potential selection bias in the elderly. Epidemiology. 2008 May;19(3):448-50. 